[DOI: 10.24214/jecet.A.8.3.22230]

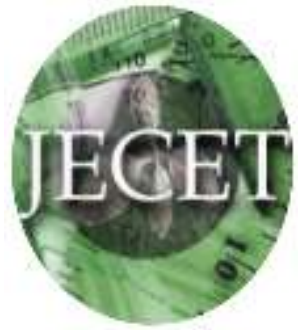

Jaurnal of Enviranmental Science, Computer Science and Engineering \& Technology

An International Peer Review E-3 Journal of Sciences and Technology

Available online at www.jecet.org

Section A: Environmental Science

Research Article

\title{
Impact of Atmospheric Resources in the Collected Water of Mirash Landfill
}

\author{
${ }^{1}$ Florent Dobroshi, ${ }^{2}$ Ilirjan Malollari, ${ }^{3}$ Faton Maloku, ${ }^{4}$ Krenar Dobroshi \\ ${ }^{1}$ Faculty of Food Technology, University”Isa Boletini“, Mitrovica, Kosovo; \\ ${ }^{2}$ Faculty of Natural Sciences, University of Tirana, Albania; \\ ${ }^{3}$ Institution of Higher Education, UBT- College, Prshtina, Kosovo; \\ ${ }^{4}$ College of Medical Sciences "Rezonanca", Prishtinë, Kosovo;
}

Received: 25 May 2019; Revised: 13 June 2019; Accepted: 20 June 2019

\begin{abstract}
The state of surface water and groundwater in the Mirash landfill and around it is at a critical point and the whole situation shown is due to inadequate and inadequate management of inadequate and harmful human activities for the environment around the landfill and perhaps inappropriate location selection. Recognizing the state of surface and underground waters in the surrounding area of Mirash landfill and the surface mine site complex, it should be considered that inadequate management of these resources could lead to a disaster of unforeseen magnitude in the contamination of groundwater. The purpose of this paper is primarily to: Assessment of the impact of the collected water at the Mirash landfill in the social and health aspects of people and other environmental impacts. Identification of precipitation effects in the collected waters of the Mirash landfill, and their common impact on the surface waters and groundwater. The methodology to be used during this work and study will be oriented to: Collection of literature and data about the
\end{abstract}


study area. Taking samples of the collected water at the Mirash landfill, Analysis of collected samples.Presentation of data using statistics, graphics, maps etc. Therefore we consider this work to be a significant contribution to the identification of environmental problems in the Mirash landfill and the possibilities for their rehabilitation.

Keywords: landfill, research, content, water drainage, metals indicators.

\section{INTRUDUCTION}

During the deposition process, we reproduce and generate pure and accumulated water and such clusters will contain highly pathogenic pollutants ${ }^{[1-3]}$, toxic chemicals that are harmful to humans and the ecosystem in general and after a certain period of time we will also have the processes of biodegradation of organic matter and as a result we will have the appearance of ammonia, methane, $\mathrm{H}_{2} \mathrm{~S}$ and other pollutants ${ }^{[4-6]}$.

Throughout history, the development of civilization and human progress has often been linked to the development and advancement of regular waste management. The man has always insisted that the remnants produced leave them away from where they lived, adjusting and covering them. Waste collection and inadequate care has become a global problem of humanity, with the increasing tendency to endanger the environment ${ }^{[7-10]}$ where it surrounds us. For the last four decades, the European regulations described intensively follow the development of the concept of waste management, with the tendency of reducing the amount of waste both created and deposited.

Waste management is one of the most priority questions at the most diverse levels, both European and world level ${ }^{[11-13]}$. The rules adopted by the EU show that among the initial relevant environmental acts that are defined in the common chapters on environmental protection from harmful human actions and impacts, it is mainly related to waste problems and inadequate care ${ }^{\text {[14-16]. }}$

In 2008, the so-called Waste Directive (2008/98 EU) ${ }^{[17-19]}$ was adopted, which has amended and amended several earlier directives. And based on this we can derive the definition of waste where:

Waste is considered under the law on waste management any substance or object the holder throws, is intended or is obliged to cast.

Waste is divided into groups, subgroups and types of waste by their properties and place of creation.

Classification and division of waste can be done in different ways depending on the nature of their study. A more complete and complete division of waste into all types of waste is as follows:

(a) Division by origin, the nature of their creation; according to the nature of decomposition, their solubility; according to volatility; according to the place of creation. Solid waste by origin can be: origin of nature, and of anthropogenic origin.

(b) All solid waste components, whether natural or anthropogenic, shall be composed of: 
Organic: Fermentable which are quickly decomposed eg. waste from food, bones, dead bodies etc.

Inorganic: Inert (organic and inorganic), which dissolve very slowly like ceramics, glass, plastics etc.

Depending on the characteristics of the risk that affect the lives of people and the environment, the debris can be: Non-hazardous waste; inert waste; Hazardous waste.

The breakdown by country of their creation is as follows: municipal wastes, commercial wastes, industrial wastes.

\section{MATERIALS AND METHODS}

Generation of municipal waste in Kosovo by regions is shown in Figures 1. and 2.

The data presented show that the largest amount of waste during 2009 has been deposited at Pristina landfill (84,660.59 tons), while the smallest amount was collected at the Sharr landfill (4807.00 tons). If we compare the data for waste deposited in sanitary landfills for 2009, until 2013 it is noticed that in all regional and municipal landfills there were larger quantities of waste disposal.

Whereas waste collection data by regions for the period 2009-2013 are presented graphically as in Figure 2.

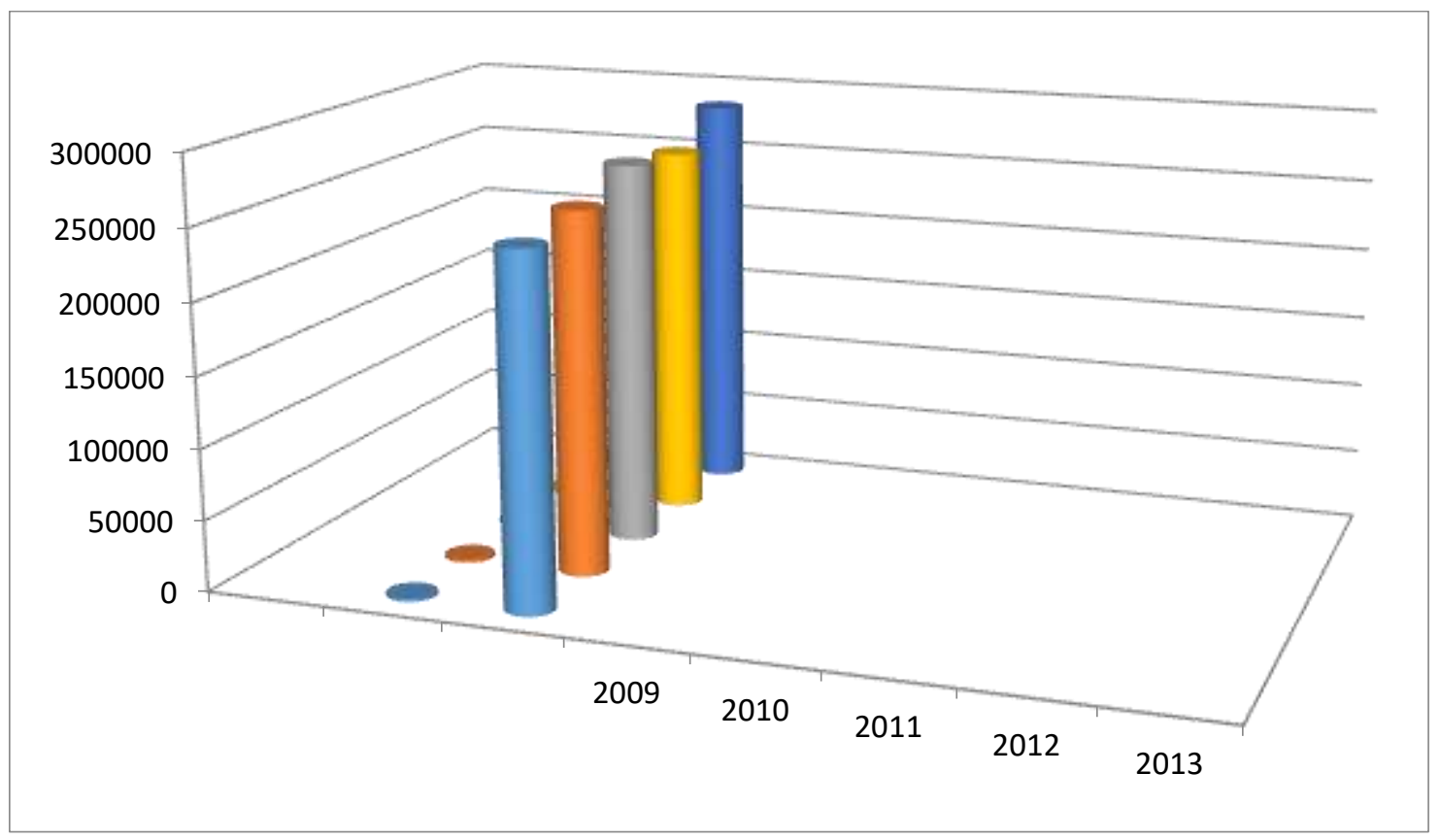

Figure 1: Quantity of waste deposited in sanitary landfills 2009-2013 


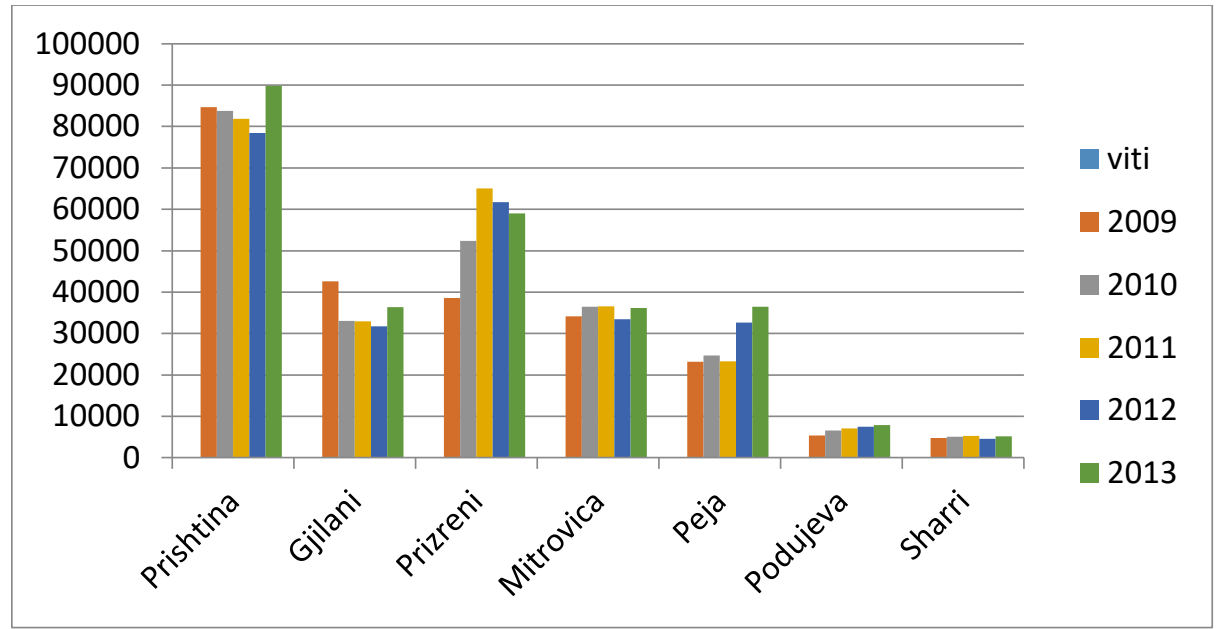

Figure 2: Quantity of waste collection by regions 2009-2013

\section{RESULTS AND DISCUSSIONS}

The experimental part of this paper was conducted in the laboratories of the Hydrometeorological Institute of Kosovo. During the research and the numerous analyzes we have used different chemicals that were needed to determine the many parameters in the wastewater analysis of waste at Mirash. For this purpose, we have used contemporary methods of determining parameters such as: spectrophotometric method, atomic absorption spectroscopy method, and in very rare cases classical standard methods of analysis. Sampling is done after a lagoon survey and site surveys.

A serious account was taken of sampling in order to enable conclusions to be drawn for their mutual comparison. Standard sampling tools and containers were used. For the determination of the parameters of the wastewater sludge samples in Mirash we have used these devices and instruments: for the conductance measurement of the electric conductivity and the $\mathrm{pH}$ is used a conductor $\mathrm{pH} /$ CONDUCTANCE METER 3320 concentrations measurements of most anions and cations have been made direct reading Spectrofotometer Prim Secoman; The measurements of heavy metal concentrations were made with Atomic Absorber Perkin Elmer, while some other chemical parameters (GO, $\left.\mathrm{SHBO}_{5}, \mathrm{KTO}, \mathrm{MTS}, \mathrm{NO}_{3}, \mathrm{DET}\right)$ were made with direct reading Spectrofotometer Pastel.uv Secoman.

Water monitoring is usually done in order to obtain information on the levels of pollutants in a water environment or organisms that live in it and that are affected by these substances. An important place for monitoring water is taking and storing samples. The manner of sampling is not the same for different analytical techniques and methods. This should be adapted to both the technique and the purpose of the analysis. Determination of the parameters of waste water in Mirash: Water temperature; Electricity Quest; pH value; turbidity; Chlorurate; Total suspended materials; Content of nitrogen in water; Sulfate; Dissolved Oxygen (OT); Dry Oxygen Expansion (GOO); Biochemical Oxygen Expenditures (OAAs) and Heavy Metals. 
Determination of chemical parameters prior to rainfall: The dry chemical parameters of the waste landfill in Mirash have been determined in the laboratories of the Hydrometeorological Institute of Kosovo.

Determination of heavy metals, prior to atmospheric rainfall: All heavy metals in the waste water at Mirash have been determined by the Institute of Hydrometerology of Kosovo, by the method of atomic absorption spectroscopy (SAA). In the same way physical and chemical parameters are determined after the atmospheric precipitation.

\section{The results of determining parameters before the atmospheric rainfall}

(a) Physical parameters before rainfall: determined on 02.08.2017 in KHMI and we have obtained the following data:

The ambient temperature was $37.5^{\circ} \mathrm{C}$ and then the water temperature in our case is $29.5{ }^{\circ} \mathrm{C}$.

Flavor as a physical parameter is defined by smell. During the sampling of the water in the depot $t$ in Mirash, it was found that this water had a smelly flavor.The dye we have defined based on the site where, as it is noticed, the water in the lagoon of the waste dump in Mirash is yellow.

The turbidity was determined in the laboratory by the turbidimeter TURB 430 IR and we have determined that the water turbidity in the lagoon of the waste dump in Mirash is 327 NTU, where this value shows the suspended matter in water such as clay, lime, dispersed organic matter, inorganic matter, plankton and other microscopic organisms.

The electrical pertinence that represents the ability of materials to convey electricity. In the water sample for analysis, electrodes of the conductometry prepared for the measurement are placed and through the $\mathrm{pH}$ / Cond 3320 conductor we have determined that the electrical permeability of the materials in the lagoon of the waste landfill in Mirash is $4690 \mu \mathrm{S} / \mathrm{cm}$.

Total water soluble matter represents the content of all inorganic and organic substances in the form of molecular, ionized and suspended micro-granules (colloids), which is determined through the $\mathrm{pH}$ / Cond 3320 conductor and we have a value of $2345 \mathrm{mg} / \mathrm{l}$, total water soluble matter.

The hydrogen ion concentration of the $\mathrm{pH}$ is determined by $\mathrm{pH}-$ meter, $\mathrm{pH} /$ Cond 3320 in the wastewater lagoon at Mirash, having a value of 7.9. This parameter can be set up immediately after taking the ground water sample.

(b) Dry parameters before rainfall: determined on 02.08.2017 in KHMI and we have obtained the following data:

Dissolved oxygen and oxygen saturation is determined by the Oxygen Meter (Microprocessor HI 9146) and has a value of $4.5 \mathrm{mg} / \mathrm{l}$, while oxygen saturation is $59.5 \%$. Chemical oxygen expense and biochemical expense of oxygen have been determined by the type spectrophotometer (Pastel.UVSecomam), and we have determined that the chemical waste of the waste in the waste water at Mirash is $4650 \mathrm{mg} / \mathrm{l}$, while the biochemical consumption of oxygen is $2500 \mathrm{mg} / \mathrm{l}$. 
- The total organic carbon in the waste water at Mirash is $1980 \mathrm{mg} / \mathrm{l}$.

- Total suspended matter in the waste water at Mirash is $2240 \mathrm{mg} / \mathrm{l}$.

- Detergents in the waste water at Mirash are $3.20 \mathrm{mg} / \mathrm{l}$.

- Nitrates in the waste water at Mirash are $4 \mathrm{mg} / \mathrm{l}$.

- The nitrites concentration of nitrites in the waste water at Mirash is $8.31 \mathrm{mg} / \mathrm{l}$.

- Ammonia at $640 \mathrm{~nm}$ and we see that the concentration of ammonia in the waste water at Mirash is $59.8 \mathrm{mg} / \mathrm{l}$.

- Spectrophotometric phosphates at $720 \mathrm{~nm}$ and the value read for phosphate in the water at Mirash is $32.6 \mathrm{mg} / \mathrm{l}$.

- Sulfates in the wavelength of $420 \mathrm{~nm}$ and read the sulfate value that is $56.4 \mathrm{mg} / \mathrm{l}$.

- Chlorides with titrimeters result in the mass: $\mathrm{m}\left(\mathrm{Cl}^{-}\right) / \mathrm{dm}^{3}=0.248 \mathrm{~g} / \mathrm{l}=248 \mathrm{mg} / \mathrm{l}$

- Phenols with spectrophotometers, with a concentration of $3.25 \mathrm{mg} / \mathrm{l}$

(c) Heavy metals: determined by the method of atomic absorption spectroscopy (SAA).

\section{Results of determination of parameters after atmospheric rainfall}

a. Determination of physical parameters after atmospheric rainfall is done at the Hydrometeorological Institute of Kosovo.

From the results of the tests carried out, we see that there is a change of parameter values before the atmospheric rainfall and after the atmospheric rainfall. Differences can be observed in all physical parameters ranging from weather, water temperature, ambient temperature, aroma, color, blur, electrical perturbation etc.

b. Determination of chemical parameters after atmospheric rainfall is made at the same time as physical parameters. Because of the changing climate and rainfall we can notice the changes in the results before and after the atmospheric rainfall, where we can compare the experimental data.

The working procedure for finding the values of these parameters after the rainfall is the same, we used the titrimetric, spectrophotometric, conductivity and pH-meters method, whereby we defined: dissolved oxygen, oxygen saturation, chemical and biochemical oxygen demand, total suspended matter, fostates, sulphates, nitrates, chlorides, phenols etc.

c. Determination of heavy metals after atmospheric rainfall is done at the same time as physical and chemical parameters. Data on heavy metals are determined by the method of atomic absorption spectroscopy (SAA). From the experimental results we see that there is a decrease in the values of heavy metals after the atmospheric rainfall, knowing that the atmospheric waters are clean waters and because of the increase in the volume of waterfalls the level of heavy metals. 
However, despite the decrease in the values of the pollutant parameters after the atmospheric rainfall, the water status accumulated in the Mirash landfill results to be of high values of the pollutant, physical, chemical and heavy metals parameters.

\section{CONCLUSIONS}

Based on the research conducted around the collection waters at the Mirash waste dump, conclude that the chemical, physical and heavy metal determination methods. carried out prior to and after the precipitation, a serious condition was found in the accumulated waters with high pollutant parameters, tendency to further deterioration.

The level of water collected within the landfill has been steadily increasing, and the process of pumping and treatment in a plant does not exist at all, and on the other hand, based on the research it is concluded that the level of water collected within the landfill and the underground ones is that equal.

Considering that not far from the Mirash landfill graves the Sitnica River, the deposits around it contain gravelly sandy material from sands and gravel, where this will affect the fastest flow of groundwater towards the possibility of joining the purified and collected waters of landfill.

Analyzes made prior to precipitation in the collected water show high values of pollutant parameters such as organic, inorganic and heavy metals, whereas in the analyzes made after the atmospheric rainfall we have observed that in some of the polluting parameters we have decreased their concentration as the result of increased volume of accumulated water, but the overall condition is extremely critical. Underground water in the study area is not too deep, even after pumping out of the water pump from the aquifer around the landfill by KEK, the level of natural water is probably considered to be above the bottom level of the basement of the landfill, and there is a very negative development where natural water can overcome the barriers created around the landfill and join water accumulated within the landfill.

- In the Mirash landfill, it is urgently necessary to review the continuation of its operation as a result of the lack of basic elements for operation, such as the removal and treatment of wastewater and landfill gases.

- Recycling and composting initiatives should be further supported and encouraged as long as we are in use of this landfill where this would increase the living space of this sanitary landfill and reduce the generation of clusters and other pollutants.

- Analysis of groundwater samples for wells near well-drained and accumulated landfills should be done continuously according to the foreseen time standards.

- Professional and managerial training of the landfill staff as well as the development and implementation of public awareness programs for the population near and around the landfill sites.

- Centralized treatment of drained waters with a treatment plant only for landfills. 
- To have a research and operational continuity within the landfill in the future in longer periods of time as a study point for younger scientific generations.

\section{REFERENCE}

1. Dr.Sc.Tahir Soflic, Dr.Sc Ivan Brnardic, Gospodarenje Otpadom, Sisak,2003.

2. Raport për Mbeturina dhe Kimikate, Prishtinë,2014.

3. A.Çullaj, Kimia e Mjedisit, Tiranë, 2005.

4. H.G. RAMKE, Appropriate Design and Operation of Sanitary Landfills in: Sustainable Economic Development and Sound Resource Management in Central Asia, 2001.

5. A. Wells and M. Crooks, Solid Waste Landfill Design Manual, Olympia, Publication No. 8713, Washington, USA, 1987.

6. A. Jaber and A. Nasser, Assessment of solid waste dumpsites in Gaza Strip. Gaza Strip. JICA \& EQA, 2007.

7. R. Mortaja, An Investigation into Geotechnical Aspects of Landfilling (case study of Gaza). MSc thesis, Loughbouroh University, UK, 1998.

8. P. Kavanangh, Design Sanitary Landfill Mobilization Construction, Washington, D.C.20314, 1984,

9. A. Bagchi, Design, Construction and Monitoring of Landflls. 2nd Edition, John Wiley \& Sons. Inc., New York, 1994.

10. M. Monroe,Landfill Leachate Treatment,2002. www.vsep.com/.

11. C. Eden, Combined Landfill Gas Leachate Extraction System, UKPS Ltd, England, $\mathrm{UK}, 1994$.

12. J. Crawford and P. Smith, landfill Technology, John F Crawford \& Paul G Smith 1985.

13. P. O'Leary and P.Walsh, Introduction to Solid Waste Landfill, Solid and Hazardous Waste Education Center, University of Wisconsin-Madison USA, 1997.

14. A. Jouda, Solid Waste Management in Developing Countries Msc thesis, London University, $\mathrm{UK}, 1994$.

15. Golder Associates, "Re-design of Mirash - Bardh subfield landfill Kosovo: Report", Berkshire, SL6 8BY, England.2004, (nga f.1-f14)

16. A. Çullaj, Metodat fiziko-kimike të analizës, Fakulteti i Shkencave Natyrore, Universiteti i Tiranës, SHB „Libri universitar“, Tiranë, 1989.

17. N. Daci, Kimia e mjedisit (ndotja industriale - parandalimi), Akademia e Shkencave dhe e Arteve e Kosovës, Botime të veçanta XXVIII, Seksioni i Shkencave të Natyrës, Libri 5, Prishtinë,1998 
18. http://www.viridiancolombia.com/en/data/vpPumps/vpPumpsImagenIzq.jpg

19. https://www.koerting.de/en/ejectors-for-waste-water-aeration.html

\section{* Corresponding Author : Florent Dobroshi;}

Faculty of Food Technology, University ”Isa Boletini“, Mitrovica, Kosovo; 